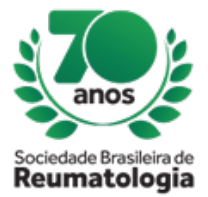

\title{
SEVERE ENTERITIS IN SYSTEMIC LUPUS ERYTHEMATOSUS
}

Sheron Zamboni (Serviço de Reumatologia do Hospital Nossa Senhora da Conceição - GHC , Porto Alegre, RS, Brasil), Jean Paulo Veronese de Souza (Serviço de Medicina Interna do Hospital Nossa Senhora da Conceição - GHC , Porto Alegre, RS, Brasil), Camila de David Cruz (Serviço de Reumatologia do Hospital Nossa Senhora da Conceição - GHC, Porto Alegre, RS, Brasil), Marcelo Maltchik (Serviço de Reumatologia do Hospital Nossa Senhora da Conceição - GHC, Porto Alegre, RS, Brasil), Paulo Roberto Lerias Almeida (Serviço de Medicina interna do Hospital Nossa Senhora da Conceição - GHC, Porto Alegre , RS, Brasil), Deise Marcela Piovesan (Serviço de Reumatologia do Hospital Nossa Senhora da Conceição - GHC, Porto Aelgre, RS, Brasil), Bárbara Mendes da Silva (Serviço de Reumatologia do Hospital Nossa Senhora da Conceição - GHC, Porto Alegre, RS, Brasil), Markus Bredemeier (Serviço de Reumatologia do Hospital Nossa Senhora da Conceição - GHC, Porto Alegre , RS, Brasil)

\section{BACKGROUND}

Lupus enteritis is relatively rare, affecting 0.2 to $5.8 \%$ of SLE patients, with mortality estimated in about $11 \%$. The pathophysiologic mechanism involves inflammation and/or vasculitis of the small intestine caused by deposition of immune complexes and complement activation. It rarely occurs as an isolated disease activity finding. Symptoms of lupus enteritis range from mild anorexia and abdominal pain to sudden, intense pain, accompanied or not by vomiting, nausea and diarrhea. Possible complications include intestinal perforation, gastrointestinal bleeding, and obstruction. Initial evaluation with contrasted abdominal CT identifies parietal and mesenteric edema and dilatation of small intestinal loops, abnormal bowel enhancement ("target sign"), ascites, engorgement of mesenteric vessels ("comb's sign"), and frequently signs of pseudo-obstruction. The use of high dose corticosteroids alleviates symptoms and reduces inflammatory intestinal activity. In refractory cases, the use of azathioprine, cyclophosphamide or rituximab has obtained good results, preventing complications. Predictive factors of relapse are refractory symptoms after corticoid treatment and inflammatory cystitis or urethritis on flare onset.

\section{CASE REPORT}

A 41-years-old woman with Systemic Lupus Eritematous (SLE) was admitted to the hospital due to a sudden intense abdominal pain, distention, nausea and vomiting unrelieved by analgesics and scopolamine. She was taking hydroxychloroquine, prednisone $5 \mathrm{mg} /$ day, mycophenale mofetil (for lupus nephritis), and recently thalidomide (for refractory discoid lupus). She was also under treatment for hypertension, and used to smoke more than 20 cigarettes/day. Laboratory evaluation revealed consumption of C3 $(56 \mathrm{mg} / \mathrm{dL}), C$-reactive protein $=50,1 \mathrm{mg} / \mathrm{L}$, erythrocyte sedimentation rate $=71$ $\mathrm{mm} / \mathrm{hr}$, normal amilase and lipase levels. Abdominal computed tomography (CT) showed distention of small intestine loops, parietal thickening of the small intestine with target pattern of contrast enhancement (Figure 1), ascites and comb's sign (Figure 2). The patient was submitted to a three-day course with $500 \mathrm{mg}$ of intravenous metilprednisolone, with significant improvement of symptoms. After 10 days, the pain returned despite maintenance therapy with prednisone $60 \mathrm{mg} / \mathrm{day}$, and she was readmitted. She then received additional treatment with intravenous cyclophosphamide (1000 $\mathrm{mg})$, leading to a complete recovery from the abdominal and systemic symptoms within a few days.

\section{CONCLUSION}

Evaluation of abdominal pain is a medical challenge, even when there are clues to a specific etiology. In SLE patients this challenge can be even bigger owing to the use of multiple medications, the immunosupressed state, and possible commitment by the disease itself. Treatment with immunosupressants may be necessary for patients refractory to corticosteroids. 